\title{
ANALISIS PENDAPATAN USAHATANI KANGKUNG (Ipomoea reptans poir) JALAN SUKAMARA KELURAHAN LANDASAN ULIN UTARA KECAMATAN LIANG ANGGANG KOTA BANJARBARU PROVINSI KALIMANTAN SELATAN
}

(Analysis Of Kangkung Farming Income (Ipomeae reptans poir) at Sukamara Road, Northern Landasan Ulin Village, Liang Anggang District, Banjarbaru City, South Kalimantan Province)

\section{Wasdiyanta}

Prodi Agribisnis, Fakultas Pertanian Universitas Achmad Yani Banjarmasin Wasdiyanta26@gmail.com

Article Submitted : 06-4-2020

Article Accepted : 04-6-2020

\begin{abstract}
This research takes the title of the analysis of kangkung farming income (ipomeae reptans poir) The observation was carried out on Sukamara Street in March 2020 with a simple random sampling method. This research was conducted by survey method with participatory observation techniques, the purpose of this research is to find out how to cultivate water spinach farming and how much is the total cost and income in one growing season the results of the study obtained a total cost of Rp. 34,570,305, -, receipt of Rp. 67,554,000, - so the income is Rp. 32,983,685,-
\end{abstract}

Keywords : Kangkung farming income

\section{PENDAHULUAN}

Tanaman kangkung (Ipomoea reptans poir) dikenal masyarakat Indonesia termasuk dalam sayuran daun. Tanaman ini diduga berasal dari daerah tropis, terutama dikawasan Afrika dan Asia. Daerah penyebaran tanaman kangkung pada mulanya berpusat (terkonsentrasi) dibeberapa negara, antara lain Malaysia dan sebagian kecil Australia kemudian meluas cukup pesat di daerah Asia Tenggara. Beberapa Negara yang merintis pembudidayaan tanaman kangkung secara intensif dan komersial adalah Taiwan, Thailand, dan Filiphina. (Abidin, Suwarna, Veggel, 1990).

Budidaya tanaman kangkung di Jalan Sukamara dilakukan secara intensif dan berorientasi kearah agribisnis sehingga diharapkan akan memberikan keuntungan yang cukup besar bagi para petani. Tanaman kangkung ini mudah dalam pemeliharaannya dan relatif murah dalam penyediaan biaya usaha lainnya. Panen dapat dilakukan setiap hari yang disesuaikan media penanaman dengan waktu pemanenan yang relative pendek \pm 30 hari. Pada keadaan pasar normal, harga tiap ikat kira-kira sekitar Rp. 1500,00 dan paling rendah Rp. 1000,00.

Perlakuan penggunaan pupuk kompos dengan menggunakan kotoran kelinci akan berpengaruh terhadap pertumbuhan tanaman kangkung darat. (Irawati Z. 2013)

Sektor pertanian umumnya dilaksanakan oleh petani di bawah garis kemiskinan. Dimasa yang akan datang pembangunan pertanian non padi diperkirakan merupakan kunci pertumbuhan pertanian rakyat, peningkatan penyerapan tenaga kerja dan peningkatan pendapatan petani (Simatupang, 1994 ; 74). Untuk mengetahui pendapatan usahatani tanaman Kangkung (Ipomoea 
reptans poir) di Jalan Sukamara maka dilakukan penelitian ini.

Tujuan dilakukan penelitian ini adalah secara Teknis untuk mengetahui Budidaya tanaman kangkung (Ipomoea reptans poir) di Jalan Sukamara dan secara ekonomis untuk mengetahui biaya, penerimaan, dan pendapatan usahatani kangkung di Jalan Sukamara

Tanaman Kangkung (Ipomoea reptans poir) dapat ditanam di dataran rendah dan dataran tinggi. Kangkung merupakan jenis tanaman sayuran daun, termasuk dalam famili Convolvulaceae. Daun kangkung panjang, berwarna hijau keputih- putihan merupakan sumber vitamin pro vitamin A. Berdasarkan tempat tumbuh, kangkung dibedakan menjadi dua macam yaitu: 1) Kangkung darat, hidup di tempat yang kering atau tegalan, dan 2) Kangkung air, hidup ditempat yang berair dan basah. Kedua macam kangkung tersebut memerlukan sejumlah besar bahan organik (kompos) dan air agar tanaman ini dapat tumbuh dengan subur (Edi dan Yusri, 2010).

Dalam kondisi tanah yang berpasir salah satunya tanaman yang dapat tumbuh adalah Ipomoea sp seperti yang ditemukan di daerah kawasan pantai. Spesies-spesies tumbuhan lain yang dapat hidup di daerah tersebut antara Amaranthus sp, dan Spinifex sp. (anonim, 2014).

Kangkung dapat ditanam dari biji benih atau keratin akar. Kangkung sering ditanam pada semaian sebelum dipindahkan di kebun. Daun kangkung dapat dipanen setelah enam minggu ditanam. Jika penanaman basah digunakan, potongan sepanjang 12-inci ditanam dalam lumpur dan dibiarkan basah. Semasa kangkung tumbuh, kawasan basah ditenggelami pada tahap 6 inci dan aliran air perlahan digunakan. Aliran air ini kemudian dihentikan apabila tanah harus digemburkan. Panen dapat dilakukan 30 hari setelah penanaman. Apabila pucuk tanaman dipetik, cabang dari tepi daun akan tumbuh lagi dan dapat dipanen setiap 7-10 hari. Semasa berbunga, pucuk kangkung tumbuh dengan lambat, dengan pengolahan tanah dan panen cenderung menggalakkan lebih banyak daun yang dihasilkan (Primantoro,1996).

\section{METODE PENELITIAN}

Penelitian dilaksanakan di Jalan Sukamara Landasan Ulin Kota Banjarbaru, selama 3 bulan mulai bulan Maret sampai Mei 2020. Penelitian ini dilaksanakan dengan metode survai dengan teknik observasi partisipasi. Data primer dikumpulkan melalui wawancara langsung dengan petani responden yang dibantu dengan daftar pertanyaan/questioner. Data sekunder dikumpulkan dari instansi-instansi pemerintah yang terkait. Penarikan contoh menggunakan teknik acak sederhana. Pengambilan sampling yakni sebanyak 20 orang dari 40 petani kangkung yang melaksanakan budidaya tanaman kangkung.

\section{Analisis Data}

Menurut Boediono (1982;95), untuk mengetahui total penerimaan dirumuskan sebagai berikut:

$\mathbf{T R}=\mathbf{P} \times \mathbf{Q} \ldots$

Dimana : TR

$=$ Total revenue $/$

$$
\begin{aligned}
& \text { penerimaan total }(\mathrm{Rp}) \\
& \mathrm{P}=\text { = Price } / \text { harga }(\mathrm{Rp}) \\
& \mathrm{Q} \quad=\text { Quantity / Produksi } \\
& (\mathrm{Kg})
\end{aligned}
$$

$\mathbf{T E C}=\Sigma$ pi. Xi $\ldots \ldots \ldots \ldots \ldots$ (II)

Dimana :

TEC = Total Ekplixit Cost/ Biaya Eksplixit Total (Rp)

$\mathrm{Pi}=$ harga per unit ke-i $(R p)$

$\mathrm{Xi}=$ jumlah input atau factor produksi ke-l $(R p)$

I $\quad=$ Input yang digunakan $I=1,2,3$,

Untuk mengetahui pendapatan digunakan rumus (Syaripuddin 1995;36) sebagai berikut :

$\mathbf{I}=\mathbf{T R}-\mathbf{T E C}$

Dimana :

$\mathrm{I} \quad=$ Income / pendapatan $(\mathrm{Rp})$

$\mathrm{TR}=$ Total Revenue / Penerimaan total $(\mathrm{Rp})$ 


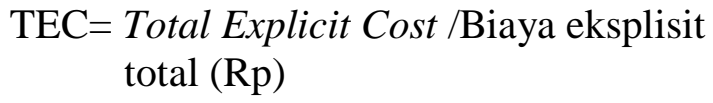

\section{KEADAAN UMUM DAERAH}

\section{Letak dan Luas Daerah}

Jln Sukamara merupakan salah satu yang termasuk dalam wilayah Kecamatan Liang Anggang Provinsi Kalimantan Selatan. Terletak $3 \mathrm{~km}$ dari Kelurahan Guntung Payung dengan batas - batas wilayah sebagai berikut :

- Sebelah Utara berbatasan dengan Kab.Banjar

- Sebelah Selatan berbatasan dengan Kab.Tanah Laut

- Sebelah Barat berbatasan dengan Kab.Banjar

- Sebelah Timur berbatasan dengan Kec.Landasan Ulin

Luas Sukamara 400 ha, terdiri dari beberapa bagian sesuai dengan penggunaan dan keperluan masyarakat akan tanah, antara lain untuk perumahan, pekarangan dan sawah.

\section{Keadaan Iklim}

Tipe iklim wilayah penelitian dapat dihitung dengan menggunakan perhitungan menurut Schmidt dan Ferguson di dalam Khirstomaman (21:2004) dengan cara menghitung jumlah bulan kering dan bulan basah dari tiap-tiap tahun kemudian diambil rata - ratanya. Berdasarkan peritungan, maka Sukamara Liang Anggang termasuk tipe iklim B, yaitu beriklim basah, dengan perbandingan $\mathrm{Q}(0,32)$ berada pada kisaran $0,143 \leq Q<0,333$

\section{HASIL DAN PEMBAHASAN}

\section{Identifikasi Petani Responden}

Keberhasilan dalam
penyelenggaraan usahatani, sangat
ditentukan oleh faktor sosial, terutama dalam
hal identifikasi petani responden, yang
diamati dalam penelitian ini meliputi : umur
petani, tingkat pendidikan, jumlah
tanggungan keluarga dan luas lahan garapan.

\section{Umur Petani}

Umur rata-rata petani responden adalah 45,76 tahun, dengan kisaran antara 21 tahun sampai 55 tahun. Dari seluruh petani yang ada semuanya usia produktif yaitu 20 orang atau $100 \%$. Menurut Salladien, (1981) jenis kelompok umur usia 0 - 14 tahun belum produktif, 15 tahun - 54 tahun produktif dan 55 keatas tidak produktif.

\section{Pendidikan}

Tingkat pendidikan petani contohnya adalah sekolah dasar/sederajat sampai tingkat SLTA/sederajat. Dalam kegiatan usahatani tingkat pendidikan ini berpengaruh terhadap kemampuan petani untuk menyerap suatu teknologi baru. (Lampiran 2)

\section{Luas Lahan}

Luas lahan yang dimiliki petani contoh rata-rata 494,m2 dengan kisaran $485-500 \mathrm{~m} 2$ atau rata-rata 0,0494 ha seperti dilihat pada lampiran. Status pemilik lahan, menurut hasil wawancara dengan petani responden adalah merupakan lahan milik sendiri, lahan merupakan salah satu faktor produksi yang digunakan dalam mengusahakan pertanaman, dimana tanah merupakan suatu media tumbuh tanaman.

\section{Aspek Teknik Usahatani Kangkung Benih}

Petani responden menanam varietas local, pemilihan benih untuk bibit bertanam dilakukan dengan cara menyeleksi kualitas benih unggul dari varietas Bangkok Lp.l yang ada dipasaran. Keperluan benih adalah sebesar $147 \mathrm{~kg}$ dengan rata-rata sebesar 5.9 $\mathrm{kg} /$ petani atau sebesar 1 19,4kg/ha.

\section{Persiapan Lahan}

Penyangkulan bedengan yang siap diolah dicangkul sedalam 20-25 cm kemudian perataan pada media akan mempengaruhi petumbuhan tanaman dengan dilakukan kembali penyiraman sebelum dilakukan penanaman agar biji tidak timbul keatas permukaan media karena kekurangan air, dengan luas bedengan panjang $10 \mathrm{~m}-20$ 
$\mathrm{m}$ dan lebar $1 \mathrm{~m}-120 \mathrm{~cm}$ dengan lebar drainase $30 \mathrm{~cm}$.

\section{Penanaman}

Benih yang memenuhi persyaratan untuk ditanam di lahan permanen yang sudah disiapaan. Pembudidayaaan kangkung pada media pasir tidak dilakukan pembibitan karena mempengaruhi pertumbuhan kangkung yang kurang maksimal, $\mathrm{pH}$ tanah yang digunakan 5-6 dengan 3-4 biji dengan jarak $5 \mathrm{~cm} \quad x \quad 10 \mathrm{~cm}$. Setelah selesai penanaman kemudian dilakukan penyiraman agar benih yang sudah ditanam tertutup dengan media pasir dan yang harus tetap basah dan selalu terjaga kandungan airnya.

\section{Pemeliharaan Tanaman}

Adalah suatu perlakuan khusus pada tanaman agar bisa tumbuh dan berkembang sesuai yang diharapkan. Adapun pemeliharaan meliputi :

a. Penyiraman

Penyiraman dilakukan memenuhi kebutuhan tanaman akan air sehingga tidak mengalami kekeringan yang dapat mengakibatkan tanaman layu dan mati, selain itu juga untuk mengganti air yang hilang diserap tanaman atau karena penguapan. Penyiraman dilakukan dua kali sehari yaitu pagi jam 07.00 dan sore jam 17.00 wita akan tetapi jika turun hujan penyiraman tidak dilakukan.

b. Pemupukan susulan

Pemupukan susulan perlu dilakukan untuk menambah unsur hara dan meningkatkan hasil panen secara kualitatif maupun kuantitatif. Pemupukan dilakukan pada kangkung setelah berumur 5 hari menggunakan pupuk kandang sebanyak 2 karung (70 $\mathrm{kg}$ ) dengan cara ditebarkan di sekitar tanaman, pemupukan susulan dilakukan pada umur 13 hari setelah tanam menggunakan pupuk urea dengan dosis sebesar $2 \mathrm{~kg}$. Sedangkan Pupuk NPK dengan dosis sebesar $5 \mathrm{~kg}$. Pemupukan dilakukan pada hari yaitu antara jam 07.00-08.00 wita. c. Penyiangan

Penyiangan dilakukan 2-4 kali selama masa pertanaman Kangkung (Ipomoea reptans poir), disesuaikan dengan kondisi keberadaan gulma pada bedengan penanaman.penyiangan dilakukan I atau 2 minggu setelah penanaman.Yaitu mencabut rumput yang tumbuh di sekitar tanaman, dengan tujuan agar makanan yang diperlukan oleh tanaman tidak terbagi-bagi sehingga proses pertumbuhan dapat maksimal dan dilakukan pada pagi/sore hari.

\section{Panen dan Pasca Panen}

Waktu panen harus tepat yaitu jika umur kangkung sudah mencapai standar pemanenan, dilakukan secara manual dan pada pagi hari dan sore hari agar kangkung tetap segar tidak cepat layu. Tanaman kangkung langsung diikat pada saat dilakukan pemanenan menggunakan karet dan ditampung ditempat teduh setelah itu pemanenan dilakukan pencucian pada akar tanaman kangkung agar bersih dan segar, setelah itu disimpan ditempat dingin dan teduh dapat mempertambah kesegaranya.

Panen Kangkung ketika berumur sekitar 20-30 hari setelah tanam dipanen dengan cara mencabut sebagaian tanaman dimana pada petani contoh rata-rata 300 ikat $(120 \mathrm{~kg})$ dalam satu hari, pemanenan dilakukan setiap hari pada pagi hari atau sore hariapabila ada permintaan dari luar daerah.Tanaman kangkung langsung diikat pada saat dilakukan pemanenan penggunakan karet dan ditampung ditempat teduh setelah itu pemanenan dilakukan pencucian pada akar tanaman kangkung agar bersih dan segar. Produksi yang dihasilkan pada usahatani kangkung di Jalan Sukamara sebesar $33.777 \mathrm{~kg}$ dengan rata-rata sebesar $1.689 \mathrm{~kg} /$ petani atau $(0,033777 \mathrm{ton} / \mathrm{ha})$.

\section{Analisis Usahatani Kangkung}

\section{Biaya Eksplisit}

Biaya eksplisit adalah biaya yang nyata dikeluarkan. Menurut Soekartawi (1995) 
biaya dapat klasifikasikan menjadi 2 (dua) yaitu : Biaya tetap (Fixed Cost), yaitu semua biaya yang dikeluarkan dalam penyelenggaraan usaha tani jumlahnya tetap dan terus dikeluarkan walaupun produksi yang diperoleh banyak atau sedikit. Biaya variable (Variable Cost), yaitu biaya yang dikeluarkan berubah- berubah atau biaya yang besar kecilnya dipengaruhi oleh jumlah produksi yang diperoleh, seperti biaya bibit, pupuk, obat-obatan, tenaga kerja dan lainlain.

\section{Biaya Sarana produksi}

Biaya sarana produksi ini terdiri dari biayarata-rata untuk kebutuhan benih petani contoh 5.9 Kg (Rp.206.360,-) pupuk urea rata-rata $9 \mathrm{~kg}$ (Rp. 16.848,-) pupuk NPK 28 kg (Rp. 79.296,-), pupuk kandang 614 kg (408.310,-) dan biaya Pestisida gramoxon rata-rata I botol Rp. 50.000,- untuk tiap tiap petani responden.

\section{Biaya Penyusutan Alat}

Biaya alat perlengkapan dihitung dengan menggunakan perhitungan nilai penyusutan dari alat tersebut yang tidak habis di pakai dalam sekali proses produksi. Nilai penyusutan dihitung dengan menggunakan metode garis lurus, alat-alat yang ada berupa parang dengan harga Rp.2.604,17, cangkul dengan harga Rp 3,750,75, karung dengan harga Rp 5.266,71, ceret air dengan harga Rp. 2.083.33 dan hand speyer Rp. 8.333.33.

\section{Biaya Tenaga Kerja Luar Keluarga}

Rata-rata biaya tenaga kerja luar keluarga usahatani Kangkung (Ipomoea reptans) adalah prngolahan tanah sebesar Rp. 555.000,-, penanaman sebesar Rp. 75.000,-, perawatan sebesar Rp. 176.250 dan pasca panen sebesar Rp. 150 total rata-rata biaya tenaga kerja luar keluarga sebesar Rp. 956.250,-

\section{Penerimaan dan Pendapatan usahatani Kangkung}

\section{Penerimaan}

Menurut Soekartawi (1995 : Hal. 54), penerimaan adalah sejumlah satuan hasil (output) dikalikan dengan harga hasil persatuan, penerimaan usaha tani didefinisikansebagai salah satu nilai produksi total usahatani jangka usaha tertentu. Penerimaan dari usahatani Kangkung (Ipomoea reptans poir) diperoleh dari hasil perkalian antara produksi total dengan harga kangkung yang berlaku pada saat itu, dimana total produksi dari seluruh luas lahan petani responden adalah 33.777 $\mathrm{kg}$ dikali dengan harga saat itu adalah $\mathrm{Rp}$ $2.000,-/ \mathrm{kg}$. Jadi penerimaan rata-rata sebesar Rp 3.377.700.,- petani per musim

\section{Pendapatan}

Pendapatan adalah selisih antara penerimaan dengan biaya eksplisit total (biaya nyata yang dikeluarkan). Pendapatan yang diperoleh seorang petani adalah imbalan yang diperoleh keluarga petani dari penggunaan faktor produksi, tenaga kerja dan modal yang diinvestasikan kedalam bidang usaha (Bishop, 1978). Pendapatan petani dihitung dari pengurangan jumlah penerimaan dengan seluruh biaya total eksplisit. Pendapatan petani dipengaruhi oleh tinggi rendahnya tingkat produksi, harga produk, dan biaya eksplisit serta luas lahan yang diusahakan.

Pendapatan petani dari seluruh usahatani Kangkung (Ipomoea reptans poir) rata-rata sebesar Rp. 1.649.185,-- per petani per musim tanam yang dihasilkan dari pengurangan penerimaan sebcsar Rp 3.377.700,- per petani per musim tanam dikurangi seluruh biaya total eksplisit sebesar Rp. 1.728.515,- . Besarkecilnya pendapatan diperoleh petani tidak terlepas dari kondisi lahan setempat, kondisi pasar, serta bagaimana penggunaan faktor produksi secara efisien, karena dengan menekan biaya produksi diharapkan pendapatan yang diperoleh akan lebih besar. 


\section{KESIMPULAN}

1. Secara teknis budidaya tanaman kangngkung di Jalan Sukamara masih manual dan belum menggunakan mekanisasi pertanian

2. Secara ekonomis Biaya total yang dikeluarkan dalam satu kali budi daya Kangkung (Ipomoea reptans poir) sebesar Rp.34.570.305,- atau rata-rata sebesar Rp.1.728.515 per petani. Untuk penerimaan sebesar Rp.67.554.000,atau rata-rata sebesar Rp. 3.377.700,per petani, dan pendapatan sebesar Rp 32.983.685,- per petani atau pendapatan rata-rata per petani sebesar petani Rp 1.649.185,- pertanam.

\section{DAFTAR PUSTAKA}

Abidin, Suwarna, Veggel, 1990. Berbagai Kepadatan Tanan Terhadap Pertumbuhan Dan Hasil Dua Kultivar Tanaman Kangkung Darat (Ipomeae reptans poir. Bogor

Bappenas, 2005. Revitalisasi Pertanian, Perikanan, dan Kehutanan (RKPPK). Buku II, Jakarta.

Anonim, 2016. Pengantar Metode Statistik Jilid II. Penerbit LP3ES. Jakarta
Irawati, Z. 2013. Pertumbuhan Tanaman Kangkung Darat (Ipomeae Reptans poir) Dengan Pemberian Pupuk Organik Berbahan Dasar Kotoran Kelinci, Jurnal Bioedukatika, Volume 1

Simatupang, Pantjar, M.H., Togatorop,R.P. Sitompul dan T. Tambunan., 1994. Prosiding Seminar Nasional Peranan Strategis Industri Kecil dalam Pembangunan Jangka Panjang Tahap II, UKI-Press, Jakarta. http;/wwwe.ekonomirakyat.org. Diakses tanggal 17 November 2017

Soekartawi, 1995. Analisis Usahatani. Penerbit Universitas Indonesia (UIPress). Jakarta

Syarifuddin A. Kasim, 1995. Pengantar Teori Ekonomi Pertanian. Buku I Universitas Lambung Mangkurat Press. Banjarbaru 
Lampiran 1. Biaya Tenaga Kerja Luar Keluarga

\begin{tabular}{|c|c|c|c|c|c|c|c|c|c|c|}
\hline \multirow{2}{*}{ No } & \multicolumn{2}{|c|}{ Pengolahan Tanah } & \multicolumn{2}{|c|}{ Penanaman } & \multicolumn{2}{|c|}{ Pemeliharaan } & \multicolumn{2}{|c|}{ Panen } & \multicolumn{2}{|c|}{ Jumlah } \\
\hline & HKO & Biaya (Rp) & HKO & Biaya (Rp) & HKO & $\begin{array}{c}\text { Biaya } \\
(\mathrm{Rp})\end{array}$ & HKO & $\begin{array}{c}\text { Biaya } \\
(\mathrm{Rp})\end{array}$ & $\mathrm{HKO}$ & $\mathrm{Rp}$ \\
\hline 1 & 6 & 450.000 & 1 & 75.000 & 3 & 225.000 & 2 & 150.000 & 12 & 900.000 \\
\hline 2 & 6 & 450.000 & 1 & 75.000 & 2 & 150.000 & 2 & 150.000 & 11 & 825.000 \\
\hline 3 & 8 & 600.000 & 1 & 75.000 & 5 & 375.000 & 2 & 150.000 & 16 & 1.200 .000 \\
\hline 4 & 8 & 600.000 & 1 & 75.000 & 3 & 225.000 & 2 & 150.000 & 14 & 1.050 .000 \\
\hline 5 & 6 & 450.000 & 1 & 75.000 & 3 & 225.000 & 2 & 150.000 & 12 & 900.000 \\
\hline 6 & 6 & 450.000 & 1 & 75.000 & 3 & 225.000 & 2 & 150.000 & 12 & 900.000 \\
\hline 7 & 8 & 600.000 & 1 & 75.000 & 2 & 150.000 & 2 & 150.000 & 13 & 975.000 \\
\hline 8 & 10 & 750.000 & 1 & 75.000 & 2 & 150.000 & 2 & 150.000 & 15 & 1.125 .000 \\
\hline 9 & 10 & 750.000 & 1 & 75.000 & 2 & 150.000 & 2 & 150.000 & 15 & 1.125 .000 \\
\hline 10 & 6 & 450.000 & 1 & 75.000 & 2 & 150.000 & 2 & 150.000 & 11 & 825.000 \\
\hline 11 & 4 & 300.000 & 1 & 75.000 & 2 & 150.000 & 2 & 150.000 & 9 & 675.000 \\
\hline 12 & 8 & 600.000 & 1 & 75.000 & 2 & 150.000 & 2 & 150.000 & 13 & 975.000 \\
\hline 13 & 10 & 750.000 & 1 & 75.000 & 2 & 150.000 & 2 & 150.000 & 15 & 1.125 .000 \\
\hline 14 & 10 & 750.000 & 1 & 75.000 & 2 & 150.000 & 2 & 150.000 & 15 & 1.125 .000 \\
\hline 15 & 10 & 750.000 & 1 & 75.000 & 2 & 150.000 & 2 & 150.000 & 15 & 1.125 .000 \\
\hline 16 & 6 & 450.000 & 1 & 75.000 & 2 & 150.000 & 2 & 150.000 & 11 & 825.000 \\
\hline 17 & 6 & 450.000 & 1 & 75.000 & 2 & 150.000 & 2 & 150.000 & 11 & 825.000 \\
\hline 18 & 4 & 300.000 & 1 & 75.000 & 2 & 150.000 & 2 & 150.000 & 9 & 675.000 \\
\hline 19 & 8 & 600.000 & 1 & 75.000 & 2 & 150.000 & 2 & 150.000 & 13 & 975.000 \\
\hline 20 & 8 & 600.000 & 1 & 75.000 & 2 & 150.000 & 2 & 150.000 & 13 & 975.000 \\
\hline Jumlah & 148 & 11.100.000 & 20 & 1.500 .000 & 47 & 3.525.000 & 40 & 3000.000 & 255 & 19.125.000 \\
\hline Rerata & 7 & 555.000 & 1 & 75.000 & 2 & 176.250 & 2 & 150.000 & 13 & 956.250 \\
\hline
\end{tabular}

Tingkat upah yang berlaku di Sukamara Kecamatan Liang Anggang adalah sebesar Rp. 75.000 / $\mathrm{HKO}$ 
Lampiran 2. Jumlah dan Biaya Sarana Produksi pada Usahatani Kangkung (Iphomoea reptans poir) di Sukamara Tahun 2020

\begin{tabular}{|c|c|c|c|c|c|c|c|c|c|c|c|}
\hline \multirow{3}{*}{ No } & \multicolumn{2}{|c|}{ Benih } & \multicolumn{2}{|c|}{ Pupuk Urea } & \multicolumn{2}{|c|}{ Pupuk NPK } & \multicolumn{2}{|c|}{ Pupuk Kandang } & \multicolumn{2}{|c|}{ Gramoxon } & \multirow[b]{2}{*}{ Biaya Sapodi } \\
\hline & Jumlah & Biaya & Jumlah & Biaya & Jumlah & Biaya & Jumlah & Biaya & Jumlah & Biaya & \\
\hline & $(\mathrm{kg})$ & $\mathrm{Rp}$ & $(\mathrm{kg})$ & $\mathrm{Rp}$ & $(\mathrm{kg})$ & $\mathrm{Rp}$ & $(\mathrm{kg})$ & $\mathrm{Rp}$ & $(\mathrm{kg})$ & $\mathrm{Rp}$ & $\mathrm{Rp}$ \\
\hline 1 & 6 & 210,000 & 10 & 18,000 & 27 & 75,600 & 700 & 465,500 & 1 & 50,000 & 819,100 \\
\hline 2 & 6 & 210,000 & 10 & 18,000 & 28 & 78,400 & 600 & 399,000 & 1 & 50,000 & 755,400 \\
\hline 3 & 6 & 210,000 & 10 & 18,000 & 30 & 84,000 & 600 & 399,000 & 1 & 50,000 & 761,000 \\
\hline 4 & 5 & 175,000 & 9 & 16,200 & 25 & 70,000 & 600 & 399,000 & 1 & 50,000 & 710,200 \\
\hline 5 & 6 & 175,000 & 10 & 18,000 & 28 & 78,400 & 600 & 399,000 & 1 & 50,000 & 720,400 \\
\hline 6 & 6 & 210,000 & 10 & 18,000 & 27 & 75,600 & 600 & 399,000 & 1 & 50,000 & 752,600 \\
\hline 7 & 6 & 210,000 & 10 & 18,000 & 29 & 81,200 & 600 & 399,000 & 1 & 50,000 & 758,200 \\
\hline 8 & 6 & 210,000 & 9 & 16,200 & 29 & 81,200 & 600 & 399,000 & 1 & 50,000 & 756,400 \\
\hline 9 & 6 & 210,000 & 9 & 16,200 & 28 & 78,400 & 600 & 399,000 & 1 & 50,000 & 753,600 \\
\hline 10 & 6 & 210,000 & 9 & 16,200 & 30 & 84,000 & 600 & 399,000 & 1 & 50,000 & 759,200 \\
\hline 11 & 6 & 210,000 & 10 & 18,000 & 30 & 84,000 & 600 & 399,000 & 1 & 50,000 & 761,000 \\
\hline 12 & 6 & 210,000 & 10 & 18,000 & 30 & 84,000 & 600 & 399,000 & 1 & 50,000 & 761,000 \\
\hline 13 & 6 & 210,000 & 9 & 16,200 & 25 & 70,000 & 650 & 432,250 & 1 & 50,000 & 778,450 \\
\hline 14 & 6 & 210,000 & 10 & 18,000 & 28 & 78,400 & 600 & 399,000 & 1 & 50,000 & 755,400 \\
\hline 15 & 5 & 210,000 & 8 & 14,400 & 29 & 81,200 & 600 & 399,000 & 1 & 50,000 & 754,600 \\
\hline 16 & 6 & 175,000 & 9 & 16,200 & 29 & 81,200 & 600 & 399,000 & 1 & 50,000 & 721,400 \\
\hline 17 & 6 & 210,000 & 9 & 16,200 & 26 & 72,800 & 650 & 432,250 & 1 & 50,000 & 781,250 \\
\hline 18 & 6 & 210,000 & 10 & 18,000 & 27 & 75,600 & 620 & 412,300 & 1 & 50,000 & 765,900 \\
\hline 19 & 6 & 210,000 & 9 & 16,200 & 30 & 84,000 & 600 & 399,000 & 1 & 50,000 & 759,200 \\
\hline 20 & 6 & 210,000 & 10 & 18,000 & 30 & 84,000 & 580 & 385,700 & 1 & 50,000 & 747,700 \\
\hline \multirow[t]{2}{*}{ Jumlah } & 118 & $4,095,000$ & 190 & 342,000 & 565 & $1,582,000$ & 12,200 & $8,113,000$ & 20 & $1,000,000$ & $15,132,000$ \\
\hline & 5.9 & 204,750 & 9.5 & 17,100 & 28.3 & 79,100 & 610.0 & 405,650 & 1 & 50,000 & 756,600 \\
\hline
\end{tabular}

Sumber : Hasil Pengolahan Data Primer Tahun 2020

Keterangan :

Kebutuhan benih dalam 1 kali musim tanam (1 bulan) 5,9 kg

Harga benih 1 bungkus (1 kg) Rp 35.000

Harga Pupuk Urea Rp 1.800 / kg

Harga Pupuk NPK Rp 2.800 / kg

Pupuk Kandang @ Rp.665,-

Harga Gromoxon Rp 50.000 / botol 
Lampiran 3. Jumlah Biaya Alat Perlengkapan pada Usahatani Kangkung (Iphomoea reptans poir)

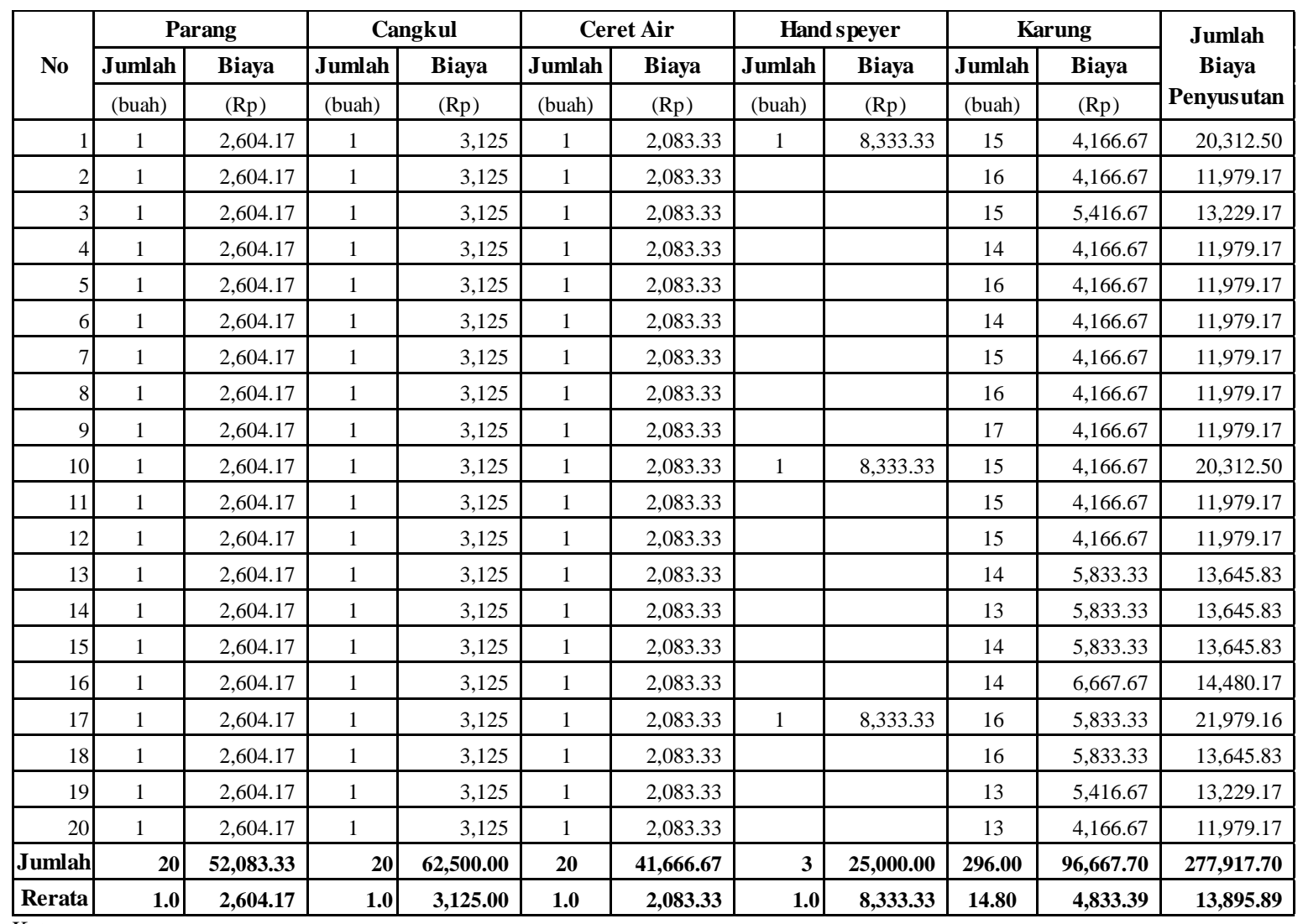

Keterangan :

Harga parang Rp 125.000,-/ buah, usia ekonomis 4 tahun

Harga cangk Rp 150.000,-/ buah, usia ekonomis 4 tahun

Harga karung Rp 5.000,-/ buah, usia ekonomis 1 tahun

Harga hand sprayer Rp 400.000,-/ buah, usia ekonomis 4 tahun

Harga Ceret Air Rp 50.000,-/ buah, usia ekonomis 2 tahun 
Lampiran 4. Jumlah Biaya Eksplisit Pada Usaha Tani Kangkung Di Jalan Sukamara

\begin{tabular}{|c|c|c|c|c|}
\hline No & Biaya Sapordi & $\begin{array}{c}\text { Biaya Penyustan } \\
\text { Alat }\end{array}$ & Biaya TKLK & $\begin{array}{c}\text { Jumlah Biaya Eksplisit } \\
\text { (Rp) }\end{array}$ \\
\hline 1 & 819,100 & 20,312 & 900,000 & $1,739,412$ \\
\hline 2 & 755,400 & 11,979 & 825,000 & $1,592,379$ \\
\hline 3 & 761,000 & 13,229 & $1,200,000$ & $1,974,229$ \\
\hline 4 & 738,200 & 11,979 & $1,050,000$ & $1,800,179$ \\
\hline 5 & 755,400 & 11,979 & 900,000 & $1,667,379$ \\
\hline 6 & 752,600 & 11,979 & 900,000 & $1,664,579$ \\
\hline 7 & 758,200 & 11,979 & 975,000 & $1,745,179$ \\
\hline 8 & 752,900 & 11,979 & $1,125,000$ & $1,889,879$ \\
\hline 9 & 750,100 & 11,979 & $1,125,000$ & $1,887,079$ \\
\hline 10 & 738,200 & 20,312 & 825,000 & $1,583,512$ \\
\hline 11 & 761,000 & 11,979 & 675,000 & $1,447,979$ \\
\hline 12 & 761,000 & 11,979 & 975,000 & $1,747,979$ \\
\hline 13 & 771,450 & 11,979 & $1,125,000$ & $1,910,096$ \\
\hline 14 & 755,400 & 13,464 & $1,125,000$ & $1,894,046$ \\
\hline 15 & 744,100 & 13,464 & $1,125,000$ & $1,882,746$ \\
\hline 16 & 749,400 & 13,464 & 825,000 & $1,588,880$ \\
\hline 17 & 774,250 & 21,979 & 825,000 & $1,621,229$ \\
\hline 18 & 765,900 & 13,464 & 825,000 & $1,454,546$ \\
\hline 19 & 759,200 & 10,119 & 675,000 & $1,744,319$ \\
\hline 20 & 747,700 & 1,1979 & 975,000 & $1,734,679$ \\
\hline Jumlah & $15,170,500$ & 271,576 & $18,975,000$ & $34,570,305$ \\
\hline Ratarata & 758,525 & 13,579 & 948,750 & $1,728,515$ \\
\hline
\end{tabular}

Lampiran 5. Penerimaan UsahaTani kangkung

\begin{tabular}{|c|c|c|c|c|c|c|}
\hline \multirow[t]{2}{*}{ No } & \multirow[t]{2}{*}{ Jenis } & \multirow{2}{*}{$\begin{array}{c}\text { Luas } \\
\left(\mathbf{M}^{2)}\right.\end{array}$} & \multicolumn{2}{|c|}{$\begin{array}{l}\text { Produksi } \\
\text { Tanaman }\end{array}$} & \multirow{2}{*}{$\begin{array}{c}\text { Ket } \\
(\mathbf{R p} / \mathrm{Kg})\end{array}$} & \multirow{2}{*}{$\begin{array}{c}\text { Penerimaan } \\
\text { (Rp) }\end{array}$} \\
\hline & & & (Ikat) & $(\mathrm{Kg})$ & & \\
\hline 1 & Kangkung & 490 & $4,125.0$ & 1,650 & 2000 & $3,300,000$ \\
\hline 2 & Kangkung & 500 & $4,262.5$ & 1,705 & 2000 & $3,410,000$ \\
\hline 3 & Kangkung & 500 & $4,250.0$ & 1,700 & 2000 & $3,400,000$ \\
\hline 4 & Kangkung & 485 & $4,247.5$ & 1,699 & 2000 & $3,398,000$ \\
\hline 7 & Kangkung & 500 & $4,275.0$ & 1,710 & 2000 & $3,420,000$ \\
\hline 8 & Kangkung & 500 & $4,240.0$ & 1,605 & 2000 & $3,210,000$ \\
\hline 9 & Kangkung & 500 & $3,995.0$ & 1,696 & 2000 & $3,392,000$ \\
\hline 10 & Kangkung & 500 & $4,250.0$ & 1,598 & 2000 & $3,196,000$ \\
\hline 11 & Kangkung & 500 & $4,255.0$ & 1,700 & 2000 & $3,400,000$ \\
\hline 12 & Kangkung & 490 & $4,280.0$ & 1,702 & 2000 & $3,404,000$ \\
\hline 17 & Kangkung & 490 & $4,250.0$ & 1,689 & 2000 & $3,378,000$ \\
\hline 18 & Kangkung & 495 & $4,262.5$ & 1,700 & 2000 & $3,400,000$ \\
\hline 19 & Kangkung & 485 & $4,245.0$ & 1,700 & 2000 & $3,400,000$ \\
\hline \multirow[t]{3}{*}{20} & Kangkung & 500 & $4,240.0$ & 1,705 & 2000 & $3,410,000$ \\
\hline & TAL & 9,840 & $84,692.5$ & $\mathbf{3 3 , 7 7 7}$ & 40000 & $67,554,000$ \\
\hline & a rata & 492 & $4,234.6$ & 1,689 & 2000 & $3,377,700$ \\
\hline
\end{tabular}


Lampiran 6. Jumlah Pendapatan Petani Pada usaha Tani Kangkung Di Jalan Sukamara Kecamatan Liang Anggang Provinsi Kaliman Selatan

\begin{tabular}{|c|c|c|c|c|c|c|}
\hline \multirow[t]{2}{*}{ No } & \multirow[t]{2}{*}{ Jenis } & \multirow{2}{*}{$\begin{array}{c}\text { Luas } \\
\left(\mathbf{M}^{2)}\right.\end{array}$} & \multicolumn{2}{|c|}{$\begin{array}{l}\text { Produksi } \\
\text { Tanaman }\end{array}$} & \multirow{2}{*}{$\begin{array}{c}\text { Ket } \\
(\mathbf{R p} / \mathbf{K g})\end{array}$} & \multirow{2}{*}{$\begin{array}{c}\text { Pendapatan } \\
\text { (Rp) }\end{array}$} \\
\hline & & & (Ikat) & $(\mathbf{K g})$ & & \\
\hline 1 & Kangkung & 490 & $4,125.0$ & 1,650 & 2000 & $1,560,588$ \\
\hline 2 & Kangkung & 500 & $4,262.5$ & 1,705 & 2000 & $1,817,621$ \\
\hline 3 & Kangkung & 500 & $4,250.0$ & 1,700 & 2000 & $1,425,771$ \\
\hline 4 & Kangkung & 485 & $4,247.5$ & 1,699 & 2000 & $1,597,821$ \\
\hline 5 & Kangkung & 495 & $4,250.0$ & 1,700 & 2000 & $1,732,621$ \\
\hline 6 & Kangkung & 450 & $4,250.0$ & 1,700 & 2000 & $1,735,421$ \\
\hline 7 & Kangkung & 500 & $4,275.0$ & 1,710 & 2000 & $1,674,821$ \\
\hline 8 & Kangkung & 500 & $4,240.0$ & 1,605 & 2000 & $1,320,121$ \\
\hline 9 & Kangkung & 500 & $3,995.0$ & 1,696 & 2000 & $1,504,921$ \\
\hline 10 & Kangkung & 500 & $4,250.0$ & 1,598 & 2000 & $1,612,488$ \\
\hline 11 & Kangkung & 500 & $4,255.0$ & 1,700 & 2000 & $1,952,021$ \\
\hline 12 & Kangkung & 490 & $4,280.0$ & 1,702 & 2000 & $1,656,021$ \\
\hline 13 & Kangkung & 480 & $4,247.5$ & 1,712 & 2000 & $1,513,904$ \\
\hline 14 & Kangkung & 500 & $4,275.0$ & 1,699 & 2000 & $1,503,954$ \\
\hline 15 & Kangkung & 490 & $4,242.5$ & 1,710 & 2000 & $1,537,254$ \\
\hline 16 & Kangkung & 490 & $4,250.0$ & 1,697 & 2000 & $1,805,120$ \\
\hline 17 & Kangkung & 490 & $4,250.0$ & 1,689 & 2000 & $1,756,771$ \\
\hline 18 & Kangkung & 495 & $4,262.5$ & 1,700 & 2000 & $1,945,454$ \\
\hline 19 & Kangkung & 485 & $4,245.0$ & 1,700 & 2000 & $1,655,681$ \\
\hline \multirow[t]{3}{*}{20} & Kangkung & 500 & $4,240.0$ & 1,705 & 2000 & $1,675,321$ \\
\hline & TOTAL & 9,840 & $84,692.5$ & $\mathbf{3 3 , 7 7 7}$ & 40000 & $32,983,665$ \\
\hline & Ratarata & 492 & $4,234.6$ & 1,689 & 2000 & $1,649,185$ \\
\hline
\end{tabular}

